\title{
Figuras da imediaticidade na retórica visual da publicidade
}

\section{RESUMO}

O propósito deste texto é apresentar a questão do "imaginário de comunicação", próprio às imagens publicitárias contemporâneas, a partir da discussão sobre o modo como o tema do grotesco é trabalhado por elas, no plano de seu discurso visual (isto é, a partir da matéria icônico-plástica de suas imagens).

\section{PALAVRAS-CHAVE}

- olhar testemunhal

- retórica visual

- fotografia

\section{ABSTRACT}

The aim of this text is to present the question of a "communicational imagination", an aspect which is allegedly proper to the contemporary visual images in advertising: we intend to present this discussion, departing from the standpoint of the ways by which the visual discourse of these images addresses the themes of grotesque (both in their plastic and iconical traits).

\section{KEY WORDS}

- visual witness

- visual rhetoric

- photography

\section{Angie Biondi e Benjamin Picado UFBA}

\section{A estilística do grotesco e o "olhar testemunhal" na imagem publicitária}

a exploração que aqui propomos sobre as estratégias discursivas próprias ao universo das imagens publicitárias, vários itens de nossa pesquisa sobre fenômenos de discursividade visual entram em jogo, ao mesmo tempo: em primeiro lugar, propomos uma análise dos dispositivos retóricos da mensagem visual na publicidade, valorizando os aspectos mais ligados à modelação icônica do discurso visual, em oposição a certas vertentes semiológicas que concebem o valor comunicacional da imagem como uma decorrência da submissão dos regimes plásticos e icônicos da representação aos padrões enunciativos do segmento lingüístico da mensagem publicitária. ${ }^{1}$

Uma vez posta a necessidade de uma maior valorização da porção plástico-icônica dos operadores discursivos na imagem publicitária, é todo um novo conjunto de aspectos constituintes da retórica publicitária que vemos emergir para nossa atenção, no momento em que nos empregamos à análise do fenômeno da discursividade própria aos ícones visuais: devotados que estamos agora ao problema do recurso a uma estilística do grotesco, na caracterização de certos gêneros do discurso publicitário contemporâneo, notamos que a análise dos materiais que exprimem esta predileção se manifestam enquanto realização discursiva ou retórica, sob dois aspectos principais: de um lado, a expressão do grotesco na publicidade é a resultante de uma série de operações ligadas aos modos de se compor a imagem, a partir do recurso a certos materiais. Uma análise das formas de realização desse discurso são certamente aquelas que vimos privilegiando na pesquisa, como um encontro das abordagens semióticas da análise de materiais visuais junto com vertentes da história e das teorias da arte que valorizam a perspectiva psicológica dos fatos artísticos. ${ }^{2}$

O segundo aspecto a se destacar, numa abordagem desses materiais, é o fato de que a retórica do grotesco na imagem publicitária se realiza através de certas operações que constituem a imagem enquanto uma espécie de centro de tensões relativamente às condições de sua recepção: melhor dizendo, o efeito do grotesco na publicidade se realiza na base da constituição de um tipo de ambiência para a representação, e que a conforma enquanto testemunho visual.

Nestes termos, a análise das operações retóricas na imagem deve destacar não apenas os elementos composicionais ou internos da imagem, mas igualmente a dimensão na qual o lugar estrutural da recepção é inscrito na própria forma do discurso 
dos ícones visuais. O efeito de retórica visual deste tipo de recurso na imagem publicitária é o de instaurar uma espécie de dobra no interior da representação, que é precisamente o espaço em que a matéria plástica e icônica da imagem passa a interpelar a recepção: certos autores se referem a este fenômeno como uma espécie de "rompimento" do espaço próprio à imagem, enquanto mera representação, incluindo em seus aspectos, a imediaticidade da presença do espectador, transformado agora numa espécie de testemunha da cena. ${ }^{3}$

Delimitamos aqui a relação entre os recursos retóricos e a matéria visual como aspecto composicional de um discurso muito próprio ao domínio da comunicação publicitária. Dada enquanto texto visual, podemos dizer que a imagem publicitária tem como objetivo principal ser captada de uma só vez. Mas esta imediaticidade (sendo da ordem de um efeito de modelação e não uma propriedade intrínseca do ícone) requer que certos operadores estejam mobilizados, a partir de princípios que são constitutivos da estrutura interna da imagem, e que favorecem esta apreensão quase instantânea da imagem pelo espectador (não nos referimos unicamente às condições perceptivas aqui, mas à aderência ou inclusão do espectador no espaço visual a partir de um posicionamento do olhar. $)^{4}$

A imagem publicitária (assim como o recurso ao estilo grotesco que caracteriza uma de suas tópicas mais recorrentes em nossa época) participa de uma estrutura assumidamente própria ao regime discursivo dos ícones, sobretudo em contextos mediáticos, e que prima pelo apagamento dos traços de sua enunciação (isto é, se constroem de modo a elidir de sua recepção o fato de que são duplos, representações): mais claramente, estas imagens tentam se instaurar como sendo o espaço de um testemunho direto daquilo que elas exibem, sem que haja entre a imagem e sua percepção qualquer tipo de intermediação ou interrupção. Os operadores através dos quais este efeito de imediaticidade se realiza são muito variados, e freqüentemente explorados a partir dos aspectos mais vinculados às estruturas lingüísticas da retórica publicitária (o uso dos vocativos, a instauração de um clima mais conversacional do discurso, entre outros). Em nosso caso, preferimos nos deter sobre o segmento propriamente icônico ou visual da modelação deste efeito de proximidade, de modo a explorar a questão da participação do olhar na imagem como sendo a finalidade essencial de uma retórica visual própria ao universo mediático.

Indiferentemente ao efeito que as imagens da publicidade possam suscitar, o importante é destacar que elas parecem induzir no nível de sua recepção uma espécie de efeito de presença instantânea do objeto da representação. Tomando o termo "abismo" do contexto de seu uso na arte da heráldica, no qual ele significa a possibilidade de fazer um símbolo conter uma figura homóloga àquela que ele re- presenta, certos autores remetem a questão do apagamento dos traços da enunciação na representação visual, como fundado na estrutura de uma vertigem abismal: esta estrutura demarca um sem-número de manifestações do campo das artes, como no caso do teatro de Shakespeare, ou na pintura de retratos holandesa do século XVII, assim como em Magritte.

Nos casos listados, entretanto, nota-se que o artifício de fazer a representação atravessar o fosso entre ela mesma e a recepção envolve uma estratégia evidentemente distinta daquela que caracteriza as imagens contemporâneas (especialmente as do discurso da publicidade): na pintura e no teatro clássicos, o recurso ao abismo se define por uma necessidade inversa de mostrar o artifício da representação, de gerar uma dobra na própria imagem e assim colocar o enunciador em seu lugar mais visível e apropriado, o de condutor das ações narradas. Aqui, se preservam os lugares devidos ao enunciado da representação e à sua enunciação, sem que sua superposição sacrifique ou empregue em demasia a matéria mesma da representação. No caso da imagem publicitária, ao contrário, o propósito é o de instaurar uma espécie de instantaneidade da relação entre a imagem e sua apreciação, do mesmo modo que os operadores lingüísticos desta mensagem instituem uma espécie de intimidade conversacional, no plano do enunciados verbais.

As representações das quais tratamos mimetizam a comunicação: uma personagem que está 'ali' se dirige a mim. Quero dizer que estas imagens, que estão no primeiro posto dos objetos de transação, redobram a comunicação em seu interior ou, se se prefere, que os signos afetados da comunicação estão, de qualquer maneira, 'abismados' na representação ela mesma. Nesta ocorrência, o abismo não se observa mais a partir do que chamamos de a forma do conteúdo na sua expressão plena e inteira (...), mas a partir da imagem apenas, como restrita ao sistema de conformação no qual ela então se inscreve. $^{5}$

A compreensão desta estrutura organizada na qual a imagem publicitária se manifesta como fato de discurso nos favorece, do ponto de vista de uma abordagem metodologicamente mais fecunda e válida, a que desenvolvamos um modo de analisar estes materiais que caracteriza este tipo de regime discursivo da imagem como uma questão de interpretação de certos de seus operadores icônicos e plásticos. Do ponto de vista da especificação dos aspectos de uma estilística grotesca da imagem publicitária, isso implicará em uma valorização do plano das formas da expressão das mensagens visuais.

\section{As inversões irônicas e o olhar testemunhal}

Tomemos em causa esta imagem (fig. 1), de uma 



FIGURA 1

FONTE: http://www.brainstorm9.com.br/archives/cat_humans for_animals.html ACESSO EM: 18 de fevereiro de 2006

\section{FIGURA 3}

FONTE: http://www.brainstorm9.com.br/archives/cat_humans_for_animals.html ACESSO EM: 18 de fevereiro de 2006

peça publicitária de uma sociedade protetora de animais, e que se organiza ao modo de uma cena à qual supostamente somos convidados a participar, como testemunhas: um homem ajoelhado com as mãos aparentemente presas atrás das costas e que tem a cabeça sustentada na parte superior de uma mesa com um corte que permite ver parte do seu cérebro exposto. Ao lado da cabeça, dois macacos que, munidos de nos parecem talheres, se servem deste cérebro.

O modelo da representação do grotesco, de certo modo retomado por esta imagem, nos restitui a certas tópicas da representação pictórica, sobretudo na arte da alta fase do Barroco, sobretudo pela valorização dos aspectos de ambientação luminosa das situações: a imagem grotesca na publicidade parece nos reproduzir a configuração pictórica de Goya, especialmente na imagem do deus Saturno devorando um de seus filhos (fig. 2).

Apesar da expressão de sua atitude ser mais apropriada à atmosfera da situação (como expressão de uma violência desmedida, que é reforçada por to-



FIGURA 2

Goya, Saturno devorando a su hijo, 1821-23 aprox. (detalhe), Madrid, Prado.

dos os aspectos da imagem), há ainda uma espécie de correspondência entre as imagens que é da ordem da figuratividade correspondente ao tema visual, uma breve semelhança na utilização das personagens flagradas em sua ação.

Em relação às imagens da publicidade, entretanto, o tratamento do grotesco na pintura parece nortearse por uma manifestação mais estetizada de tudo aquilo que serve para exprimir o caráter inusitado ou bizarro dos temas grotescos: os aspectos de iluminação e de tratamento dos elementos de cena visam à produção de uma impressão visual, mais do que de submissão a certos regimes discursivos ou retóricos, como é claramente o caso da imagem publicitária;

$\mathrm{O}$ aspecto grotesco da imagem implica numa espécie de jogo de inversões, de caráter predominantemente irônico, e que consiste em apresentar a cena, em seu aspecto inusitado ou mesmo bizarro, mas através de certos índices de normalidade: assim sendo, temos uma situação na qual os animais devoram um homem, mas estando dispostos num tipo de cenografia quase trivial, seja em seus aspectos de ambientação e iluminação, assim como na atitude das personagens envolvidas. O caráter grotesco da situação fica como que neutralizado em seu aspecto 
de fato excepcional, pelo modo como a cena toda evoca um certo ar de familiaridade. A disposição das personagens para a ação que executam parece transcorrer de modo igualmente normal, sem qualquer menção de suspense, pânico ou horror entre eles, ao contrário, o que se nos apresenta é uma parte do cotidiano destas personagens, mas é justamente nesta cena trivial que nos tomamos de certa perplexidade pela imagem.

Uma parte do corpo humano serve de alimento para os macacos, os "miolos" que estão a ponto de ser devorados pelos animais: estes, por sua vez, demonstram certa tranqüilidade em sua atitude, quase uma polidez, pois não usam as mãos e nem estão curvados sobre uma presa devorando sua carcaça, como seria de se esperar, em se tratando de bestas; ao contrário, eles manuseiam talheres para se servir de sua presa, numa atitude, podemos dizer, própria aos humanos dotados de certa civilidade.

Nesta outra imagem da campanha (fig. 3) se configura a mesma espécie de jogo de inversões irônico, com algumas variações de tratamento: de um lado, temos a mesma situação em que os sinais que caracterizam a ação humana e a passividade animal se invertem inadvertidamente; no plano comportamental, portanto, as personagens são apresentadas de modo alternado. Diferentemente da primeira situação, entretanto, a cena não é apresentada em seu aspecto de fato corriqueiro, o que lhe confere um aspecto de rudeza sem maiores intermediações de suposta normalidade atribuída à situação.

É esta organização invertida dos valores (das atitudes) de cada um dos elementos personagens/objetos/comportamento que nos provoca o sentido de estranhamento do olhar, que lhe confere o status de imagem grotesca. Tudo aquilo que parece típico em homens e símios se exibe aqui em sinais trocados, de passividade e de urbanidade e polidez. Esta provocação dos sentidos se complementa com uma sensação de perplexidade e nojo que a atitude dos macacos suscita em nós: pois comer parte do cérebro de um homem nos é completamente estranho, violento, abjeto.

Porém, o que estamos chamando de atitude aparentemente trivial na imagem apresentada é construída de modo proposital. Tomar uma atitude humana por animais e a atitude "submissa" do animal ser tomada pelo homem configura a inversão baseada no jogo irônico, que toma a "contrariedade" como elemento de base do regime discursivo desta imagem. Tão logo reconheçamos a identificação da imagem como peça publicitária, portanto veículo de uma mensagem específica, tão logo apreendamos o texto que redunda/arremata/finaliza o significado da imagem ("don't treat others the way you don't want to be treated") compreendemos a operação deste jogo semântico em sua mensagem intencional, que responde pela instituição Humans $\mathcal{E}$ Animals (marca presente no canto inferior direito da imagem).

\section{0 modo testemunhal e o "imaginário da comunicação" na imagem publicitária}

Neste ponto, precisamos reconhecer que há um outro aspecto visual que deve ser levado em conta nesta exploração do motivo grotesco, que envolve tanto a sua representação figurativa quanto seu modo de ser construída para a recepção. Trata-se da articulação entre a configuração semântica da imagem e o modo como ela deve ser acionada pelo receptor a partir do olhar. Esta relação de complementaridade entre estes dois aspectos constitui o que Fresnault-Deruelle chama de "imaginário da comunicação", ou ainda, de um simulacro da comunicação onde a representação assume um duplo sobre si mesma para que consiga se colocar como a própria enunciação para o espectador, como se não houvesse um ponto intermediário entre eles.

Se nas imagens publicitárias observadas acima, a disposição da representação parecia nos localizar dentro do espaço de uma cena apresentada, em geral, como "coisa dada" à visão, nesta outra imagem (fig. 4), as coisas se passam de modo bem diferente: não se trata de nos dar a impressão de uma cena, mas de instituir uma espécie de situação conversacional, através da imagem; é o modo como o olhar da personagem centra a recepção em relação à imagem que confere a este ícone seu aspecto de testemunho e de estranhamento. Este olhar direto da personagem da fotografia inscreve um jogo em que se simula uma conversação direta entre a personagem e o observador rompendo o esquema enunciativo que reconhece a mensagem da peça publicitária como sendo a própria intermediária do processo comunicativo.

De modo que a imagem discursiva joga bem, desde seu interior e sob o signo falacioso da imediaticidade, com os signos da comunicação.

$\mathrm{O}$ abismo parece paradoxalmente anular as distâncias. $^{6}$

Este modo de personalização do enunciado visual parece suscitar uma reação do espectador reconhecido na função fática, indicando-o a sair de um suposto estado de inércia daquele que olha ou contempla uma imagem para dar lugar ao estabelecimento de uma recíproca deste olhar; como um outro modo de interação que se esboça quando o espectador se reconhece como o "alvo direto" deste olhar, pois a personagem da fotografia deixa clara esta intenção.

A perplexidade momentânea que corresponde à detenção da imagem em seus aspectos figurativos grotescos (um rosto deformado e monstruoso que nos olha) dá lugar ao sentido de advertência que ela (a imagem) se investe num jogo de remissão do "antes e depois" da personagem. A pequena foto $3 \times 4$ exibe um momento anterior da modelo, na qual é vista com aparência normal, sadia, e uma imagem 

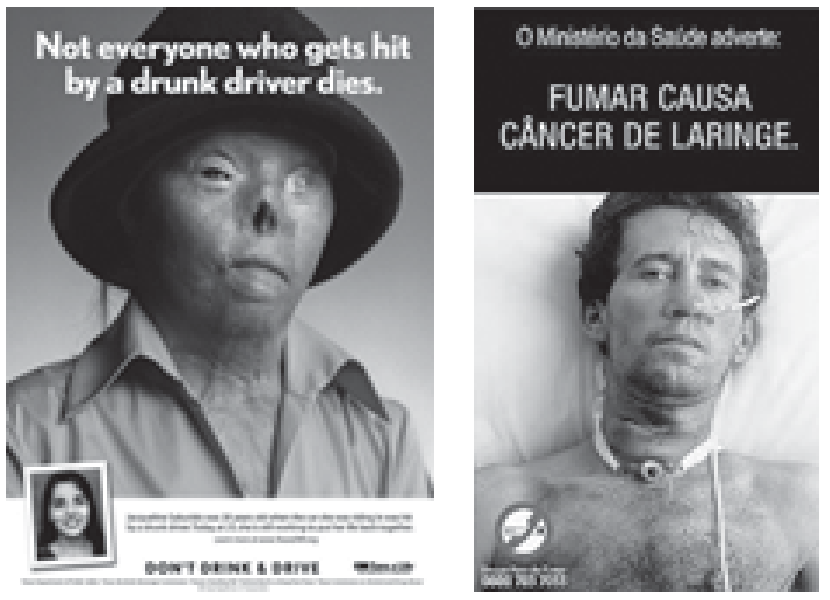

FIGURA 4

FONTE: Departamento de Transportes do Texas (TxDOT), Outubro de 2002. (cartaz de campanha)

\section{FIGURA 5}

FONTE: http://www.stopper.blogger.com.br/cig04.jpg ACESSO EM: 17 de março de 2006.

maior, sucessiva ao fato (no caso, um acidente automobilístico), numa imagem atualizada da modelo (ou melhor, da vítima). A operação disposta na relação de causa e conseqüência convoca a participação do espectador no sentido da reconstrução do percurso que gerou tal resultado.

Como num jogo causa e conseqüência, a parte que cabe ao espectador é reconstituir, imaginariamente, os acontecimentos, ainda que seja de modo geral. O reforço em atestar a conseqüência (o resultado de tal acontecimento) pode ser englobado no rol do efeito moralizador que assume o discurso publicitário aqui, sobretudo, através do modo de interação que a personagem assume conosco; ela se dirige a nós em sua posição de vítima. $\mathrm{O}$ texto que acompanha a imagem remete a este reforço de moldar um comportamento social; "não beba e dirija", diz a mensagem de rodapé do cartaz, mais uma vez, enfaticamente.

Ainda, é preciso notar que o modo pelo qual o olhar direto convoca a posição do espectador está relacionado ao valor metonímico de que se reveste a imagem. Há uma correspondência entre a apresentação da personagem como vítima e a causa do seu estado. Em boa medida, toma-se a vítima para falar do tema da imagem (acidentes por embriaguez); a sua imagem remete ao conteúdo da peça por uma condição de contigüidade. $\mathrm{O}$ mesmo tipo de jogo entre o discurso visual e o enunciativo está presente nas imagens veiculadas em maços de cigarro, por exemplo.

Contudo, convém observar que não se torna uma regra a relação que se evidencia aqui entre uma figura de discurso e um modo de olhar, inúmeras possibilidades de ordenamento entre estes aspectos podem ser combinadas numa imagem. Nosso exercício apenas enfoca alguns dos aspectos nos quais a
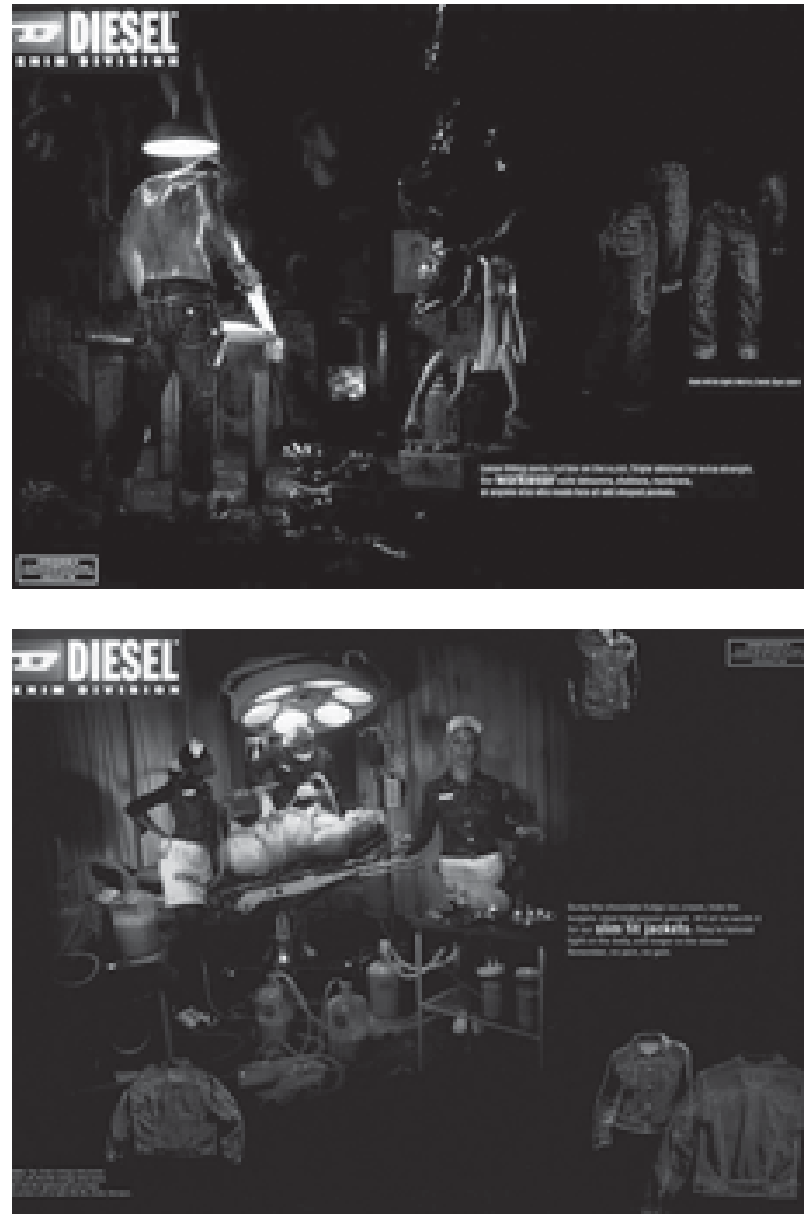

FIGURA 6

FONTE: http://www.diesel.com/sucessfullivingguides/

ACESSO EM: 23 de novembro de 2004.

\section{FIGURA 7}

FONTE: http://www.diesel.com/sucessfullivingguides/ ACESSO EM: 23 de novembro de 2004.

imagem se reveste de sentido semântico a partir das estratégias textuais que lhes são atribuídas, nos interessa investigar a estrutura de funcionamento dos operadores visuais tomada enquanto objeto oriundo da comunicação midiática.

Neste caso (fig. 5), a exposição das vítimas num estado de padecimento, de sofrimento por determinado comportamento ou atitude é tomada como uma referência direta do real. O olhar das personagens está conduzido diretamente ao espectador, ele fala ao espectador na posição de quem se dirige a ele, num relato testemunhal de qualquer ordem; se prostram como as vítimas que apresentam suas seqüelas a um público. De modo que a disposição deste olhar diretamente lançado para a recepção faz com que este possa adentrar a dimensão ficcional (ao mundo construído) da representação do mesmo modo que a personagem parece sair do espaço da imagem e se colocar diante de nós; é como se a delimitação entre as duas dimensões fosse mais porosa, mais volátil. 
O interno e o externo compartilham da consciência um do outro. É o próprio "logro da comunicação imediata" a condição da comunicação abîmée. Aqui é o presente, a atualidade da imagem que se funda no "está ai" mais do que o "haver estado ali", a condição temporal que se estabelece na imagem é o de um presente contínuo, que reenvia simultaneamente ao passado do acontecimento encarnado na personagem (nas marcas que apresentam).

Um outro aspecto que podemos notar é que nestas duas últimas figuras as personagens posam para a fotografia, ao passo que as outras sugerem "flagrantes" de determinadas situações, nas quais as personagens parecem imersas cada uma em sua ação. Tanto numa característica quanto noutra, o que se evidencia é que há uma programação do sentido préestabelecida para cada uma delas, reiterando a intenção como uma base sobre a qual se estrutura o arranjo dos elementos internos da fotografia publicitária.

Nas primeiras imagens que analisamos aqui, os elementos que a constituem se organizam na imagem ao modo de um flagrante, para as quais o fato de não haver quem olhe para a câmera é um dos recursos do qual se lança mão para repercutir com mais ênfase o mundo ficcional que se constrói, que se desenrola ali, e, o modo de construção do seu enquadramento nos torna tanto testemunhas quanto voyeurs destas cenas, ao passo que nestas duas últimas imagens, as personagens se dirigem explicitamente ao espectador através do seus olhares diretos para fora do plano, o que converte o problema do testemunho visual em uma questão de cumplicidade e de compromisso mútuo com a ordem enunciativa à qual a imagem se inscreve.

De fato há uma relação entre a pose e o olhar que cumpre uma função de indicativo testemunhal, daí cada qual ser retratado, ser destacado em sua condição de padecimento para que se estabeleça uma espécie de "pacto fiduciário" com o espectador baseado na credibilidade que a situação da personagem lhe possibilita. Na verdade, sequer pensamos nos indivíduos que nos fitam nestas imagens como sendo personagens ou modelos, mas como figuras dotadas de uma densidade biográfica com a qual nos relacionamos num nível afetivo muito mais intenso do que o de personagens de situações ficcionais: sua presença tem para nós, o valor de uma interlocução, ainda que construída como parte dos protocolos da comunicação através das imagens (o mesmo recurso é muito próprio das imagens de políticos em campanha).

No entanto, o que nossa observação sobre estes materiais nos demonstra é que há um recurso específico para dispor o espectador para a imagem. Seja através do recurso do olhar que se projeta para fora do espaço da representação ou por outro recurso, o modo como este elemento é colocado num estado de tensão arranjado com os demais elementos fotográficos (a sensação de distância pela profundidade, o enquadramento, entre outros) nos indica o percurso de sentido que se estabelece para o espectador de uma imagem.

É neste sentido que a imagem parece se projetar para fora dos limites da representação, para fora de todo suporte, como um transpassamento dos limites do plano representacional, colocando a imagem numa relação mais tensa com sua exterioridade. Neste caso, o espectador já parece incluído na cena como se ela fosse um prolongamento do seu campo visual.

A fim de fazer o leitor/espectador que participa do mundo real aderir àquele da representação, ou ainda, afim de estabelecer um terreno de concordância entre o mundo do discurso representado e o meu, a estratégia visual aqui desenvolvida consiste em fazer que eu possa me inscrever na imagem de um modo o qual descrevo agora: não fazendo mais que reatualizar, para meu corpo (...), a projeção induzida pela construção de imagens clássicas ('construção legítima'), eu me restituo deste modo em um 'antes da cena' do qual o dispositivo cênico da imagem constitui um prolongamento. ${ }^{7}$

\section{0 olhar do testemunho como "visão do flagrante"}

Há um aspecto da retórica das imagens grotescas na publicidade que resta ainda inexplorado pelas abordagens que privilegiam os aspectos textuais da representação visual: os elementos que constituem muitas destas cenas são construídos em relação a um olhar que é indexado na conformação mesma da imagem, como um dado para o qual ela se organiza: em termos, a imagem se propõe como um prolongamento da visão, constituindo uma espécie de ponto implícito da cena na qual se localiza o próprio espectador. Em linhas gerais, a imagem se constrói como um dispositivo que visa restituir a dimensão testemunhal com a qual toda sua cenografia se apresenta: ela incorpora a ordem do testemunho como um aspecto decisivo de sua significação textual.

Para certos autores que procuram explorar os limites complementares entre o valor discursivo das imagens e os aspectos plásticos e perceptuais de sua realização, o problema do "efeito de testemunho" das representações visuais é um capítulo essencial desta exploração analítica às funções textuais da imagem. Somos convocados a observar a imagem num ponto localizado implicitamente dentro dela de acordo com determinado enquadramento, com a perspectiva e a organização dos objetos de cena que estão dispostos na imagem, construindo (ou replicando) de tal modo a idéia da distância e profundidade visual a fim de que a recepção se faça presente no espaço de representação.

Nas imagens que vemos em seguida, exemplares de uma campanha de um fabricante de vestuário (figs. 6 e 7), somos novamente inscritos à cena na condição de testemunhas: mas o efeito desta cons- 
trução agora não é mais o de replicar uma situação conversacional, mas o de efetivar a participação da recepção na cena, o que faz da imagem uma espécie de símile de um testemunho ocular (agora como uma espécie de flagrante visual).

Estas imagens nos apresentam um modo de construir a impressão do grotesco, não como aspecto estritamente temático da imagem, mas como traço do modo de organização dos elementos da imagem para o olhar do espectador: neste sentido, o aspecto grotesco da cena que se nos propõe é exibido como um elemento da modelação da imagem, desde seu interior, e o modo como realiza essa organização dimensiona a imagem fotográfica enquanto cenografia.

$\mathrm{Na}$ perspectiva em que certos historiadores da arte tratam a questão da forma através da qual o olhar testemunhal é construído na representação pictórica, o elemento central da geração deste efeito tem relação com a assimilação dos aspectos psicológicos da estruturação do campo visual com questões de poética das imagens: deste modo, para Gombrich, o aspecto mais importante do "efeito de testemunho" na história das representações visuais tem a ver com a regra pela qual o artista não deverá incluir na sua composição das ações elementos que não pudessem estar presentes ao olhar, uma vez dadas as condições de sua especificação, no plano icônico da representação (o que nos promete, enquanto um traço da discursividade do drama visual, que o mesmo se desenvolva, a partir de um aspecto que a obra possa especificar, dadas as condições em que ela a testemunha, isto é, que, entre outras coisas, ela se dá em perspectiva): daí, que o estilo que encontramos associado a toda esta linhagem não se define como especificação de aspectos visuais (ou como modelação icônica) sem que consideremos, ao mesmo tempo, as necessidades das quais ele se deriva (não apenas render o visível, mas instaurar por sobre suas substâncias um sentido de desdobramento, de narrativa, de discurso).

Tenhamos em conta que, ao transmitir esta experiência do testemunho ocular, a imagem serve a um duplo propósito - ela nos mostra o que se passou lá fora, mas também, por implicação, o que ocorreu ou poderia ter ocorrido a nós, física ou emocionalmente. Nós entendemos, sem muita reflexão, aonde é que deveríamos nos localizar, em relação ao evento representado, e que momento devemos compartilhar vicariamente com aquela testemunha ocular. Não há qualquer diferença de princípio entre a imagem e o instantâneo único entre milhões, dentre os quais o fotógrafo de guerra poderia sonhar. ${ }^{8}$

Os argumentos de Gombrich parecem combinarse às provocações de Fresnault-Deruelle quanto a esta construção do olhar implícito na publicidade. Este modelo de construção visual configura a inten- ção de sua relação direta com o espectador que ele denomina de comunicação em abismo. Portanto, deter estes dois aspectos como princípios pelos quais a temática recorre ao plano da expressão nos parece produzir uma espécie de esboço de um primeiro esquema de apropriação do motivo visual trabalhado pela imagem publicitária.

Pensamos que o foco aqui é observar sob quais aspectos/recursos/artifícios o grotesco começa a ser explorado pelo campo publicitário carregando uma espécie de repertório possível do tema para o espectador. Saindo de um campo onde predomina quase absolutamente a referência ao ideal e padrão de beleza vinculado aos seus produtos, há um movimento que passa pela dimensão de uma construção deste repertório visual que assinala um campo de estratégias possíveis para sua exploração. Num estudo mais detido podemos observar as inúmeras formas pelas quais um tema visual (geralmente proveniente da arte pictórica) emerge num outro modelo de apropriação e utilização. Pensamos que a emergência do grotesco atravessa este momento. afamecos

\section{NOTAS}

1 Cf. Picado, Benjamim. "Ícones, Instantaneidade, Interpretação: por uma pragmática da representação pictórica na fotografia". In: Galáxia. 9 (2005): pp. 185-198. Para uma recapitulação das abordagens semiológicas sobre o valor discursivo das representações visuais, a visão mais completa nos é oferecida por Umberto Eco, na segunda parte de $L a$ Struttura Assente.Cf.ECO, Umberto. “OOlhar Discreto: por uma semiologia das mensagens visuais". In: A Estrutura Ausente (trad. Pérola de Carvalho). São Paulo: Perspectiva (1978): pp. 98-121.

2 Cf. Picado, Benjamim. "Olhar testemunhal e representação da ação na fotografia". In: $e$ compós. 3 (2005). www.compos.org.br/ecompos: pp. 1-29.

3 Cf. Fresnault-Deruelle, Pierre. "Première Partie: crever l'écran". In: L'Éloquence dês Images. Paris: PUF (1993): pp. 23-74.

4 Dentre aqueles que procuram tratar os aspectos psicológicos dos fatos artísticos, sem dúvida Gombrich é o autor que abordou de maneira mais pregnante o problema do "efeito de testemunho", em certos gêneros de imagens pictóricas, os quais procuramos combinar aqui com as abordagens mais afeitas à estruturação textual da imagem. Cf. Gombrich, E.H.

"Standards of Truth: the arrested image and the moving eye". In: The Image and the Eye: further studies in the psychology of pictorial representation. London: Phaidon (1982): pp. 244, 277. 
5 Fresnault-Deruelle, Pierre. “La communication abîmée”. In: L'Éloquence dês Images, op.cit.: p. 26.

6 Ibid: p. 30.

7 Fresnault-Deruelle, Pierre. "La Communication abîmée", op.cit.: p. 29-30.

8 Gombrich, E.H. “Standards of Truth”, op.cit.: p. 254.

\section{REFERÊNCIAS}

BARTHES, Roland. A mensagem fotográfica, A retórica da imagem. In: O óbvio e o obtuso. Ensaios críticos III. Rio de Janeiro: Nova Fronteira, 1990.

BRANDÃO, Roberto de Oliveira. As figuras de linguagem. Série Fundamentos. São Paulo: Ática, 1989.

CERIANI, Giulia. "Représenter le silence: analyse de la campagne institutionelle Telecom Italie 2003". In et al.: Ateliers de Sémiotique Visuelle (Anne Hénault, Anne Bayert, orgs.). Paris: PUF (2004).41-50p.

ECO, Umberto. O Olhar Discreto: por uma semiologia das mensagens visuais. In: $A$ Estrutura Ausente (trad. Pérola de Carvalho). São Paulo: Perspectiva (1978): pp. 98,121.

FRESNAULT-DERUELLE, Pierre. L'éloquence des images. Images fixes III. Paris: PUF, 1993.

GOMBRICH, Ernest H. A participação do observador. In et al: Arte e ilusão: um estudo sobre a psicologia da representação pictórica. São Paulo: Martins Fontes, 1986.193-305p.

GOMBRICH, Ernest H. Standards of truth: the arrested image and the moving eye. In: The image and the eye: futher studies in the psychology of pictorial representation. London: Phaidon, 1982. 244-277p.

KAYSER, Wolfgang. O grotesco. Configuração na pintura e na literatura. São Paulo: Perspectiva, 2003.

KOSSOY, Boris. Realidades e ficções na trama fotográfica. São Paulo: Ateliê Editorial, 2002.

PICADO, Benjamim. “Ícones, Instantaneidade, Interpretação: por uma pragmática da representação pictórica na fotografia". In: Galáxia. 9 (2005): pp. 185-198.
PICADO, Benjamim. “Olhar testemunhal e representação da ação na fotografia". In: $e$ compós. 3 (2005). www.compos.org.br/e-compos: pp. 1, 29.

VÉRON, Eliseo. De l'image sémiologique aux discursivirtés: le temps d'um photo. In: Hermes. 13/14 (1994).45-64p. 